\title{
Wo ist die Mitte?
}

Gelegentlich ist nach Voroperationen oder aufgrund einer Adipositas die Linea alba zwischen den Muskelbäuchen des Musculus rectus abdominis nicht zu erkennen. Unser Autor verrät Ihnen einen einfachen Trick, wie Sie die Linea alba ausfindig machen.

Bei Längs-Laparotomien ist das exakte Eingehen durch die Linea alba nicht nur Voraussetzung für ein kosmetisch ansprechendes Ergebnis, sondern auch für ein gewebeschonendes und anatomiegerechtes Präparieren. Das Anspannen des weichen Fettgewebes unter Zug nach kaudal führt zur Kompression oberflächlicher, subkutaner Schichten: die Muskelbäuche des $M$. rectus abdominis modellieren sich und lassen die Linea alba unter dem Fettgewebe erkennen.

Dr. Andreas Wiedemann, Witten

Korrespondenz:

Dr. Andreas Wiedemann

Evangelisches Krankenhaus

im Diakoniewerk Ruhr gGmbH

Lehrstuhl für Geriatrie

der Universität Witten/Herdecke

Pferdebachstr. 27

58455 Witten

Tel. 02302/175-2521

Fax. 02302/175-2075

awiedemann@diakonie-ruhr.de

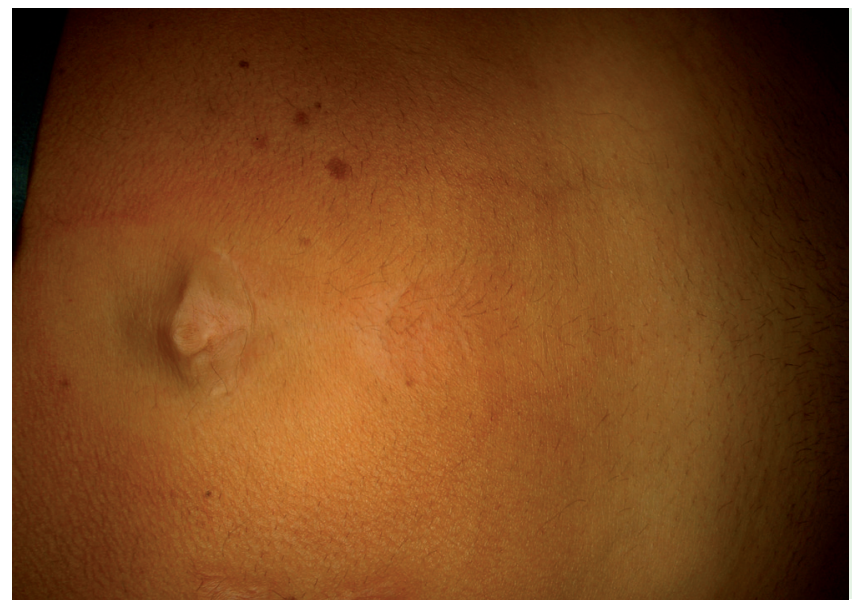

Abb. 1 Bauchdecke nativ: Die Linea alba ist nicht zu erkennen.

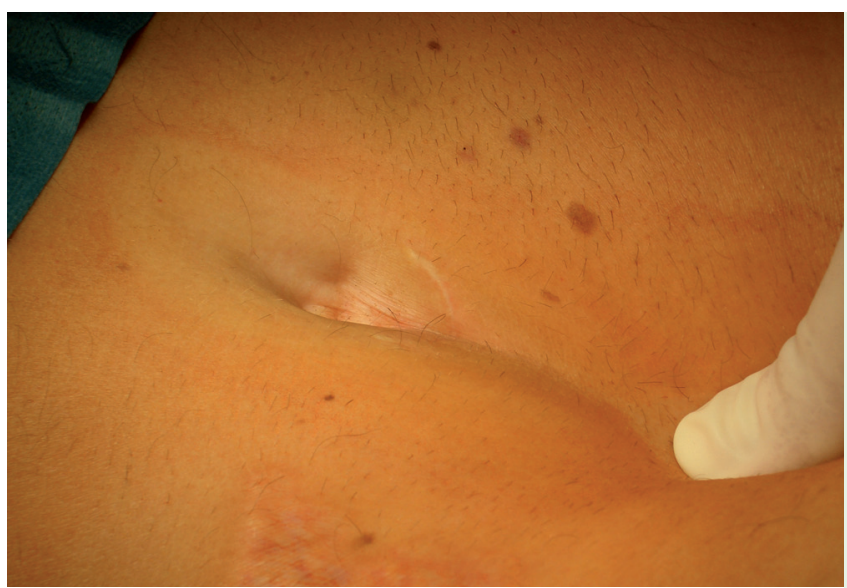

